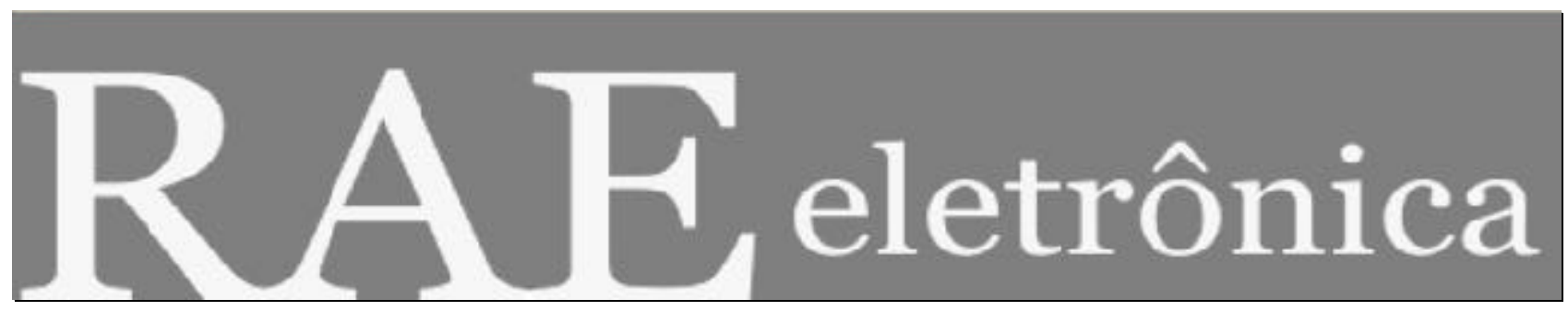

\title{
“BIBLIOMETRIA": A METODOLOGIA ACADÊMICA CONVENCIONAL EM QUESTÃO
}

Por:

Pedro Lincoln C. L. de Mattos

RAE-eletrônica, v. 3, n. 2, Art. 26, jul./dez. 2004

http://www.rae.com.br/eletronica/index.cfm?FuseAction=Artigo\&ID=2199\&Secao=DEBATE\&Volum $\mathrm{e}=3 \&$ Numero $=2 \& \mathrm{Ano}=2004$

CCopyright, 2004, RAE-eletrônica. Todos os direitos, inclusive de tradução, são reservados. É permitido citar parte de artigos sem autorização prévia desde que seja identificada a fonte. A reprodução total de artigos é proibida. Os artigos só devem ser usados para uso pessoal e nãocomercial. Em caso de dúvidas, consulte a redação: redacao@rae.com.br.

A RAE-eletrônica é a revista on-line da FGV-EAESP, totalmente aberta e criada com o objetivo de agilizar a veiculação de trabalhos inéditos. Lançada em janeiro de 2002, com perfil acadêmico, é dedicada a professores, pesquisadores e estudantes. Para mais informações consulte o site www.rae.com.br/eletronica.

\section{RAE-eletrônica}

ISSN 1676-5648

(C2004 Fundação Getulio Vargas - Escola de Administração de Empresas de São Paulo.

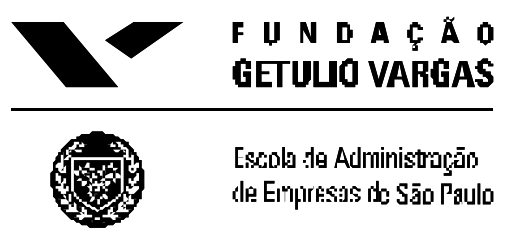




\section{"BIBLIOMETRIA": A METODOLOGIA ACADÊMICA CONVENCIONAL EM QUESTÃO}

\section{MINHA CRÍTICA, EM ESSÊNCIA}

O artigo "Pesquisa em Gestão de Recursos Humanos nos Anos 1990" faz parte de uma muito salutar política da RAE - Revista de Administração de Empresas de rever o trabalho acadêmico de Administração no Brasil no horizonte de duas décadas. Aqui, o propósito é refletir sobre ele, pensando em contribuir para que, no uso da bibliometria, se dê um passo à frente quanto à relevância e à qualidade metodológica. O texto é criativo e sugestivo, além de bem redigido. Suspeito, no entanto, que seja intenção do editor, ao me oferecer este espaço de comentários, privilegiar o questionamento - e agora lembrei-me do "spice" na citação de Bernard Shaw, aforismo com que os autores iniciam seu artigo... Vou me restringir a observações de natureza metodológica, não que haja deslizes na aplicação da bibliometria em si, mas tenho objeções de raiz ao uso dessa estratégia de pesquisa, pelo menos como ela freqüentemente ocorre. Não estaria, por essa razão, em condições de acompanhar os autores na formulação de várias de suas conclusões.

Com isso, entro em zona de risco, principalmente por tentar um passo tão ousado em tão pouco espaço. Mas a inteligência e a competência acadêmica dos autores estimulam quem tem a honra de lhes escrever uma réplica. E de um diálogo objetivo sempre surge, de uma forma ou de outra, contribuição para a academia.

O artigo usa a análise bibliométrica para "entender" e "mapear". Minha dificuldade fundamental é que a estrutura e a metodologia ali adotadas não permitem justificar por que se monta o entendimento de determinada maneira, nem por que se organiza o mapa com determinada configuração, pois haveria muitas formas de entender "a influência de autores e instituições na produção acadêmica em Recursos Humanos no Brasil na década de 1990" e de mapear "o comportamento de auto-citações e citações à própria instituição dos autores que produziram no período". Ora, a essência da contribuição conhecimento novo - está ali, no entendimento e no mapeamento. O que há é que a bibliometria, usada como estratégia estruturadora da pesquisa e não apenas como técnica auxiliar de análise de uma pesquisa já conceitualmente estruturada e fundamentada, faz os autores quase saltarem diretamente para a análise dos dados - que eles mesmos construíram de determinada maneira. Não ignoro que esse tipo de análise seja "normal e corrente em outros países", como dizem os autores ao sugerirem, eles mesmos, a grande motivação prática: "principalmente nos EUA, servindo como fonte para remuneração dos pesquisadores de diversas áreas". O fato não me impressiona, como também para ele não tenho aplausos.

Mas, sem dúvida, aí reside uma questão epistemológica muito séria, historicamente já bem tratada na filosofia do conhecimento, qual seja, a da indução em ciência - partir-se dos fatos para formulações conceituais apreciativas e conclusivas. A prática científica atual, pelo menos há meio século, na maior parte das tradições disciplinares, já incorpora, em lugar dessa lógica, a orientação hipotético-dedutiva de prova que Karl Popper bem sintetizou. É nossa prática acadêmica em Administração, por exemplo, primeiro formular suposições de problema - às vezes, hipóteses de teste - justificá-las pelos conceitos que as envolvem, apoiando-se na tradição sistematizada, teorias já bem elaboradas em confrontos anteriores com a realidade, e, só então, partir para a "operacionalização" que resulta em dados, para 
cujo entendimento de novo se recorre aos enunciados assentados de início. Esse é o método que julgo epistemologicamente sadio porque incorpora a grande crítica ao positivismo moderno (século XIX) e uma concepção mais sustentável do conhecimento generalizante, o da ciência. Penso, por conseguinte, que a bibliometria, da forma como tem sido usada - e, pareceu-me, foi usada pelos autores - no mínimo põe em questão a metodologia já tradicional na academia.

Não é possível, no espaço de uma réplica, detalhar algo da questão de fundo epistemológico acima aludida. Restrinjo-me ao trabalho desconstrutivista, crítico, mesmo sabendo ser ele o menos gratificante.

Esclareço, preliminarmente, em defesa de minha referência acima, a maneira tradicional de a academia construir seu conhecimento interpretativo, ou seja, iniciando por lhe prover apoio conceitual e teórico o que os autores não fizeram, propriamente, depois de anunciar que "no restante do artigo, discute-se a fundamentação teórica, a metodologia e os resultados do estudo". O que fizeram foi tentar credenciar o método, citando outros estudos de bibliometria e usando, no fundo, o "lugar argumentativo" (segundo os trabalhos de Perelman): se muitos fazem assim, devem estar certos, e se não, aí pelo menos não estaríamos nós errando sozinhos.

A seguir, quero estar criticando, em quatro aspectos, certo uso indevido de estatísticas de publicações em metodologia científica, mais, até, do que sua aplicação neste estudo. Sem dúvida, estendo ao presente texto, de modo geral, minhas críticas por tal uso. Tanto que, essencialmente, não o sigo em suas conclusões ou sugestões (S1 a S7). Mas não tenho espaço para indicar, a cada ponto, como os autores estariam, definitivamente, incluídos na crítica por mim dirigida ao método que usaram. Em nível mais específico, limito-me, portanto, à exemplificação.

\section{PRIMEIRO ASPECTO: A ESCOLHA DAS CATEGORIAS}

O banco de dados é construído em torno de algumas categorias, mas a escolha delas fica "atrás dos bastidores", pois o pesquisador não se sente na obrigação de se justificar no texto. No entanto, apóia-se nelas, trata-as como relevantes, inclusive quando relacionadas umas às outras, dá-lhes sentido valorativo e, no fim, cons idera os resultados da análise delas como problemas ou como avanços. No caso do artigo, são exemplos de tais categorias na organização, quase por binômios, do banco de dados: autores estrangeiros versus nacionais (problema conceitual aí envolvido: natureza sociocultural ou transcultural do conhecimento); publicações acadêmicas versus não-acadêmicas (problema conceitual: qualidade científica do conhecimento); concentração versus desconcentração institucional, contrastando com concentração versus desconcentração de veículos de publicação (problema conceitual: condições institucionais históricas do desenvolvimento científico); autores-instituições citadas versus citantes, etc. Já nas análises e conclusões encontram-se: "endogenia", "processo entrópico", "excessivamente importado", "jactâncias" e "a lamentável presença de autores de pouca ou nenhuma base acadêmica, ou profissionais de livros-texto".

No tipo de análise bibliométrica que se critica, as categorias-conceito, sobre as quais, afinal, repousa o sentido prático das conclusões, poderiam realmente ser válidas. Mas teria sido preciso estabelecer isso antes, ou de forma analítica - teórica - ou de forma "autoritativa" - alguém, amplamente aceito, argumentou nesse sentido. E não podem os autores responder a tal objeção, dizendo simplesmente: "nós apenas levantamos dados, levantamos indicadores". De fato, eles foram muito além. 


\section{SEGUNDO ASPECTO: A AMBIGÜIDADE DO SIGNIFICADO}

A ambigüidade do significado de certas análises básicas da bibliometria aparece em:

a) Citação. É tomada como apoio ou por oposição? No casso de quem contesta um autor faz algo para que não venha a ser muito citado na tradição, o contrário de quem nele se apóia. Como se podem somar coisas tão contrárias? E o que indica ser citado menos? Que sua produção é menos relevante, ou que se é um dissidente do paradigma de trabalho de um grupo, ou que há um preconceito excludente? E ser citado mais? Indica que se é preferido a outros ou que se chegou primeiro, como manual da área, principalmente em língua portuguesa? Qualquer dessas causas, ou outra? É em dificuldades assim que incorre pôr os fatos adiante das hipóteses ou não começar pelo que há de essencial no conhecimento, que é a interpretação, e não escolher um foco para o problema que tal interpretação desperta. Em função disso procuram se fatos que corroborem, neguem ou esclareçam.

b) Não-citação. Que significa? Que um autor é desconhecido, rejeitado, ou, ao contrário, que, a tomar-se pelo conteúdo do que está escrito, quem escreve identifica-se inteiramente com o não-citado formalmente - porém, de fato, seguido - e que então seria seu mentor?

c) "Idade" da obra citada. Quanto mais recente, melhor, e quanto mais antiga pior? É insustentável. Em algumas áreas é preciso trabalhar com estudos recentes, em outras, quanto mais "curtido" - pela sobrevivência à crítica intersubjetiva dos pares - melhor é o "couro"... Em outras, ainda, ambos critérios são válidos, ou não cabe isso como critério, de modo que a discriminação na contagem é certamente enganos a. Sobre esse ponto, os autores parecem algo advertidos, quando dizem: "É digno de observação que, tal como previam alguns críticos ao método, a maioria dos autores melhor classificados na amostra tem, de fato, história mais longa no campo do que os demais. Isso reforça a necessidade de o campo discutir sobre o critério desse tipo de classificação incluir ou não um ajuste ou uma ponderação em relação à idade da produção acadêmica do autor, visando à mensuração mais precisa do impacto efetivo de sua produção científica média". Mas não me parecem convictos do caráter indefinidamente recorrente do problema, por ser congênito a essa prática metodológica.

d) Autocitação. Narcisismo? Ou apenas resistência ao pudor tolo de parecer narcisista, quando se tem, de fato, estudos já elaborados cuidadosamente - e reconhecidos, pois estão publicados - sobre a matéria? Que deve preferir, então, o autor: simplesmente fazer referência ao que já disse em outra ocasião, de forma mais detalhada, ou voltar a expor idéias sobre o assunto, como se ali surgissem pela primeira vez, quando já podem ser de conhecimento do leitor?

Ora, parece que a questão da autocitação está na propriedade ou impropriedade, oportunidade ou inoportunidade da referência. O fato só se caracteriza qualitativamente. Citar-se por citar-se é tão estranho e desrespeitoso com o leitor quanto citar por citar, ou seja, de forma supérflua, como cumprindo alguma praxe formalista em que dizer pela boca de outro - seja qual for esse outro - valesse mais do que dizer com a própria.

A propósito, cabe distinguir, fundamentalmente, a referência a ensaios argumentativos ou estudos empíricos concludentes - que se usam em apoio a afirmações - de citações apenas ilustrativas, quando não se está tomando outro autor como apoio e cuja supressão não mudaria nada na força do texto. A citação aí é meio sobeja. Há, ainda, referências que são apenas breve identificação da fonte autoral mais reconhecida de significado de um conceito. Mas, infelizmente, as estatísticas não distinguem essas e outras diferenças qualitativas. E, de repente, dão-nos conclusões espetaculares, ou, no mínimo, insinuações intrigantes. 
Isso leva a falar dos "números curiosos" (agora me lembrei de Nietzsche, que observa a frequiência nas metonímias em nossa linguagem, de grande impacto no significado. Mas mantenho tal lembrança entre parênteses, para não ser, eu mesmo, acusado de fazer uma "citação sobeja").

\section{TERCEIRO ASPECTO: O QUE FAZER COM OS NÚMEROS “CURIOSOS”?}

Há uma maneira de olhar os números que encanta olhos positivistas. Ir desses números intuitivamente para a conclusão de algo certamente não seria científico. A partir deles começar uma discussão? "Começar" significa estruturar? Se sim, estamos de volta ao problema de assumir estruturas conceituais por trás dos números, não justificadas previamente. Se não, estamos diante de uma espécie de isca para o prosseguimento do trabalho investigativo. E aí, tudo bem, esses "números curiosos" serão apenas uma dentre muitas coisas com que o cientista observador se depara no mundo "em estado bruto", que chamam sua atenção e sobre as quais começa uma investigação empírica ou filosófica. Mas aí, também, estaremos de volta ao método tradicional de estruturar nossas pesquisas: a partir da definição ou discussão de uma base conceitual - teórica - interpretativa para o problema levantado. Porque, de outra forma, caberia perguntar: a simples constatação do fato "achado" no mundo e, no caso, a da "isca", pode ser chamada de contribuição para o desenvolvimento do conhecimento?

\section{QUARTO ASPECTO: O ESTILO LITERÁRIO MAL DEFINIDO}

Há o risco de se resvalar para uma zona de estilo literário mal definido. Com um monte de fatos/dados na mão tem-se sempre algo "razoável" a dizer - o leitor desavisado concordará com a interpretação, sem pedir maior análise dos conceitos e valores subentendidos. Mas isso configura uma retórica de persuasão mais do que um conhecimento objetivado em suas bases. Quem adota tal estratégia de pesquisa, como muitas vezes o faz a bibliometria, tende a, de repente, poder ser surpreendido em pleno texto jornalístico, que consiste na habilidade de levantar dados e jogar com eles.

Enfim, uma última observação, já não mais em estilo crítico. Qual o sentido de uma estatística primária, uma tabela de dados, como as do IBGE, por exemplo? O sentido ordinário da linguagem revela-se no contexto comunicativo de uso (Wittgenstein). Mesmo tal tabela "sem texto" aparece sob um tema e um título, e significa, como ato ilocucionário (Austin), que "eu afirmo a ocorrência, em certa grandeza, dessas variáveis, tal como conceituadas e identificadas em um campo de observação". Assim é a tabela entendida. Seria nonsense alguém chegar para você e dizer "eu fiz as seguintes contagens e cruzamentos: x bananas associadas a y laranjas", e ir embora. O fato significativo só surge em certo contexto de compreensão, não antes dele! Mesmo um sorteio aleatório de números tem um contexto de sentido pragmático: "eis aqui um número realmente 'qualquer', sem significado em si mesmo - não é símbolo de nada -, que usarei para uma ação extrínseca a ele”.

Portanto, um contexto significativo é posto, sim, por quem diz estar "apenas levantando números", e isso é explicitado e justificado no texto, ou não, e então se expõe às críticas acima feitas.

É por isso, também, que cons idero ingênuo o comportamento, mesmo bem intencionado, de alguns pesquisadores - e aqui de modo algum me refiro aos autores. Depois de terem montado um banco de dados, e aparentemente esquecendo- lhe as bases, eles "rodam" um software de testes de análise estatística, ansiosos por descobrir o que os números misteriosos vão revelar... Os conceitos e as relações do banco de dados interpretados pelos conceitos lógicos da matemática, na automaticidade e 
sistematicidade que a informática viabiliza, produzem um significado que o pesquisador, sem tais meios, seria incapaz de gerar. É uma interpretação! Só mudam a sintaxe e os símbolos, evidentemente mais simples que os da linguagem analítica natural! Imagino que, se o tal software, além de poderoso por encerrar o pensamento cumulativo de milhares de grandes matemáticos, coisa impossível a uma mente individual - fosse também humano e inteligente, estaria sorrindo, com piedade e ironia, do estudioso pesquisador... Enfim, fora de uma compreensão da forma como se constroem os fatos significativos, inclusive as significações quantitativas, só existem conclusões frágeis ou o fetiche dos números.

Aqui termino esta minha réplica arriscada, referindo-me de novo ao sentimento de que ela não me é gratificante. Porque toda crítica abstrai, até certo ponto, do contexto dos autores. E aí, mesmo racional e bem intencionada, pode se tornar injusta ou descabida. Aguardo a tréplica para ver se incorri em alguma ou ambas as coisas.

Artigo convidado. Aprovado em 01.11.2003.

\section{Pedro Lincoln C. L. de Mattos}

Professor Titular. PROPAD/DCA/UFPE

Interesses de pesquisa: metodologia de pesquisa em administração e epistemologia do conhecimento nessa área.

E-mail: plincoln@hotlink.com.br

Endereço: Departamento de Ciências Administrativas - CCSA. Universidade Federal de Pernambuco.

Cidade Universitária. Recife - PE, 50.670-901. 